\title{
EJE AWARD 2019 \\ New diagnostic approaches for patients with polyuria polydipsia syndrome
}

\section{Mirjam Christ-Crain ${ }^{1,2}$}

${ }^{1}$ Department of Endocrinology, Diabetology and Metabolism and Department of Clinical Research, University Hospital Basel, Basel, Switzerland and 2University of Basel, Basel, Switzerland

This article is based on the presentation for the European Journal of Endocrinology Award Lecture at the 21st European Congress of Endocrinology (ECE) 2019 held at Lyon, France

Correspondence should be addressed to M Christ-Crain Email

mirjam.christ-crain@unibas.ch

\section{Abstract}

Diabetes insipidus (DI), be it from central or nephrogenic origin, must be differentiated from secondary forms of hypotonic polyuria such as primary polydipsia. Differentiation is crucial since wrong treatment can have deleterious consequences. Since decades, the gold standard for differentiation has been the water deprivation test, which has limitations leading to an overall unsatisfying diagnostic accuracy. Furthermore, it is cumbersome for patients with a long test duration. Clinical signs and symptoms and MRI characteristics overlap between patients with DI and primary polydipsia. The direct test including vasopressin (AVP) measurement upon osmotic stimulation was meant to overcome these limitations, but failed to enter clinical practice mainly due to technical constraints of the AVP assay. Copeptin is secreted in equimolar amount to AVP but can easily be measured with a sandwich immunoassay. A high correlation between copeptin and AVP has been shown. Accordingly, copeptin mirrors the amount of AVP in the circulation and has led to a 'revival' of the direct test in the differential diagnosis of DI. We have shown that a baseline copeptin, without prior thirsting, unequivocally identifies patients with nephrogenic DI. In contrast, for the differentiation between central DI and primary polydipsia, a stimulated copeptin level of $4.9 \mathrm{pmol} / \mathrm{L}$ upon hypertonic saline infusion differentiates these two entities with a high diagnostic accuracy and is superior to the water deprivation test. Close sodium monitoring during the test is a prerequisite. Further new test methods are currently evaluated and might provide an even simpler way of differential diagnosis in the future.

\section{Invited Author's profile}

Mirjam Christ-Crain is full Professor of Endocrinology, Diabetes and Metabolism at the University of Basel and the University Hospital of Basel, Switzerland. From 2013 she has been the Deputy Chief at the Clinic for Endocrinology, University Hospital Basel and from 2014 she has been the Head of the Department of Clinical Research at the University of Basel. Her main research interest is on vasopressin-dependent disorders of fluid homeostasis, i.e. DI and hyponatremia. She has authored and co-authored more than 200 publications and received several awards for her research. Printed in Great Britain

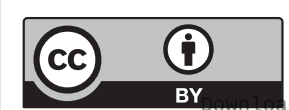

This work is licensed under a Creative Commons Attribution 4.0 International License.

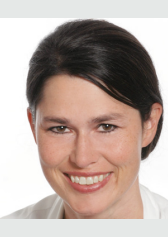




\section{Introduction}

DI (DI) belongs to the polyuria polydipsia syndrome and is characterized by a high urinary output of more than $50 \mathrm{~mL}$ per $\mathrm{kg}$ body weight per $24 \mathrm{~h}$, accompanied by polydipsia of more than $3 \mathrm{~L}$ a day (1). After exclusion of AVP-independent causes (such as hyperglycemia), the differential diagnosis of hypotonic polyuria includes central or nephrogenic DI and primary polydipsia. Differentiation is crucial since treatment varies and wrong treatment can have dangerous consequences.

Since decades, the gold standard for differential diagnosis is the classical indirect water deprivation test, which however, has its limitations and has a diagnostic accuracy of only around 70\%. To overcome these limitations, the direct test was proposed with measurement of arginine vasopressin (AVP) upon osmotic stimulation. However, despite initial promising results, this test did not enter clinical routine, mainly due to technical limitations of the AVP assay. Novel approaches are therefore urgently needed. This review focuses on new diagnostic approaches in the differential diagnosis of polyuria polydipsia syndrome.

\section{The polyuria polydipsia syndrome}

Polyuria polydipsia syndrome is a common problem in clinical practice with the main entities being central or nephrogenic DI and primary polydipsia (2).

Central DI is characterized by an insufficient vasopressin (AVP) secretion from the pituitary $(3,4)$, and nephrogenic DI results from an AVP resistance at the level of the kidneys (5). Both entities lead to hypotonic polyuria with consequent polydipsia. The most common form of central DI occurs mainly due to lesions of the posterior pituitary or the hypothalamic median eminence. A number of acquired disorders (e.g. trauma, neoplastic disease, granulomatous diseases) can lead to central DI. Transsphenoidal surgery can lead to transient central DI in up to $30 \%$ of cases and to permanent central DI in $2-10 \%$ (6). Genetic defects in the AVP synthesis can lead to inherited forms of central DI $(7,8)$. In most cases thirst mechanisms are intact, which leads to compensatory polydipsia. However, in a variant of central DI called osmoreceptor dysfunction, thirst is also impaired and hypodipsia can result in serious complications associated with hyperosmolality $(2,9)$.

Nephrogenic DI results due to a lack of aquaporin 2 (AQP2)-mediated water reabsorption in the collecting duct. This can either result from mutations in the genes encoding for the key proteins AVPR2 and AQP2 or is secondarily triggered by biochemical disorders or by certain drugs especially lithium (5).

Excessive fluid intake over an extended period of time also causes polyuria despite intact AVP secretion and renal response, but the pathomechanism is less clear. In few cases, it can result from an abnormality in thirst mechanisms (sometimes called dipsogenic DI), but more often it is due to psychiatric disorders (referred to as psychognic polydipsia). Excessive fluid intake results in a decrease in osmolality and suppressed AVP release. Consequently, water is excreted to compensate for the high fluid intake. An analysis of 23 patients with profound hyponatremia due to primary polydipsia revealed an increased prevalence for psychiatric diagnoses such as dependency disorders (43\%) and depression (35\%) (10). Another prospective study with 156 patients with polyuria polydipsia syndrome however showed a similar rate of $27 \%$ for psychiatric disorders between patients with primary polydipsia and patients with complete central DI (11). As the chronic polydipsia in patients with primary polydipsia leads to a downregulation of the AQP2 channels in the kidneys, the renal medullary concentration gradient is reduced, making any diagnostic evaluation of the urinary measures difficult (12).

\section{Differential diagnosis of polyuria polydipsia syndrome: a historic perspective}

Differentiation between the three mentioned entities is important since treatment strategies vary and application of the wrong treatment can be dangerous (13). However, reliable differentiation is often difficult to achieve (14), as available tests were unsatisfactory (15) and often resulted in false diagnoses, especially in patients with primary polydipsia or partial, mild forms of DI $(1,16)$.

\section{Clinical manifestations}

Patients with DI, especially those with osmoreceptor defect syndromes, can manifest with dehydration and hyperosmolality, if water loss cannot be compensated by fluid intake. Manifestations may range from non-specific symptoms such as irritability and cognitive dysfunction to more severe manifestations such as disorientation, reduced consciousness, seizure, coma, focal neurologic deficits and cerebral infarction (17). However, most patients have an intact thirst perception and water availability. In these 
patients the characteristic clinical symptom is polyuria and polydipsia which does not differ in manifestation between central or nephrogenic DI or primary polydipsia.

Patients with central DI are reported to have more often nocturia and a sudden onset of symptoms, resulting from the fact that urinary concentration can be maintained until the residual capacity of the hypothalamus to synthesize AVP falls below $10-15 \%$ of normal, after which urine output increases significantly. In addition, historically, it has been reported that patients with DI in contrast to patients with primary polydipsia prefer cold water as best quenching beverage and have a more sustained and less fluctuating course of symptoms (13). However, we have only recently prospectively evaluated clinical signs and symptoms: Although the majority of patients with DI indeed reported a sudden onset of symptoms, still more than one-third experienced a slow process. Moreover, also more than $60 \%$ of patients with primary polydipsia reported nightly drinking, the majority of them preferred cold beverages, and nearly $80 \%$ indicated a sustained character of symptoms. Interestingly and in contrast with the described high prevalence of psychiatric diseases in primary polydipsia, less than $30 \%$ of patients with primary polydipsia had been psychiatrically diagnosed, which was the same prevalence as found in patients with complete central DI (11). Taken together, clinical signs and symptoms are not specific and sensitive enough to differentiate between the various entities of the polyuria polydipsia syndrome.

\section{Radiological findings}

Unenhanced brain MRI via assessment of the posterior pituitary and the pituitary stalk has been reported to provide important information in the differential diagnosis of DI. Specifically, an area of hyperintensivity, referred to as the pituitary 'bright spot', is normally observed in the posterior part of the sella turcica in sagittal views on T1-weighted images (18) and is thought to result from the T1-shortening effects AVP which is stored in neurosecretory granules of the posterior lobe of the pituitary (19). However, although earlier small studies demonstrated the absence of the bright spot in patients with central DI (20), other larger studies showed that an age-related absence of a the bright spot is observed in up to $52-100 \%$ of normal subjects (21). In addition, a loss of the bright spot has also been observed in nephrogenic DI patients bearing AVPR2 mutations (22). Conversely, individual cases with persistent bright spot despite the presence of central DI have also been reported (23).
Similarly, we recently showed in a prospective largescale evaluation that the bright spot was persistent in $36 \%$ of patients with central DI, whereas it was missing in $36 \%$ of patients diagnosed with primary polydipsia. Consequently, the presence or absence of the bright spot on MRI appears not sensitive and specific enough as a diagnostic test in patients with DI.

\section{Tests for differential diagnosis}

For decades the standard diagnostic test for the evaluation of polyuria polydipsia syndrome was the indirect water deprivation test (4). Here insufficient AVP secretion or effect is diagnosed upon insufficient renal concentration capacity over a prolonged period of water deprivation and its response to exogenous AVP administration. Interpretation of the test results is based on recommendations from Miller et al. (4) according to the results of 29 patients with central DI (including 11 patients with partial DI), 2 patients with nephrogenic DI and five patients with primary polydipsia. Patients showing a urinary osmolality below $300 \mathrm{mosm} / \mathrm{kg}$ during the water deprivation test are classified as complete central DI if the urinary osmolality increased $>50 \%$ after exogenous AVP injection. Patients staying below this cut-off are diagnosed as having nephrogenic DI. Patients with partial central DI and primary polydipsia are expected to have a urinary osmolality between 300 and $800 \mathrm{mosm} / \mathrm{kg}$ upon thirsting. Urinary osmolality after AVP administration then differentiates patients with partial central DI from patients with primary polydipsia: Patients with partial central DI have an increase in urinary osmolality $>9 \%$, whereas patients with primary polydipsia remain below 9\%. However, the proposed cut-off levels were post hoc derived on a small patient cohort, showed a wide overlap in urinary osmolalities and were never prospectively validated (4).

Consequently, recent evaluations in patients with the polyuria polydipsia syndrome $(11,16)$ resulted in a diagnostic accuracy of only around $70 \%$, with an especially low accuracy in patients with primary polydipsia.

To overcome these limitations, in 1981, Zerbe et al. (24) proposed the 'direct' test, with direct measurement of plasma AVP upon osmotic stimulation. Thereby, AVP levels were evaluated in relation to the area of normality describing the physiological relationship between AVP release and plasma osmolality. Plasma AVP levels above the area of normality were defined as nephrogenic DI, levels below as central DI and levels in the normal range were defined as primary polydipsia $(7,24)$. The results clearly 
showed that direct measurement of plasma AVP had a superior diagnostic accuracy compared to the classical water deprivation test. However, despite these promising first results disappointing test results derived from recent investigations showing that AVP measurements, especially when using commercially available assays, pointed toward a correct diagnosis in only $38 \%$ of patients and were especially bad for differentiation between partial central DI and primary polydipsia (16). Possible reasons are that an accurate definition of the normal physiological relationship describing plasma AVP as a function of osmotic activity has long been missed (25). The precise definition of this normal area, however, is a fundamental prerequisite for the use of direct AVP measurement (16). Secondly, the AVP assay per se is subject to several technical limitations, resulting in a high preanalytical instability (1, 26). In addition, the few available reliable assay are not commercially available. Therefore, measurement of AVP never entered every day's clinical practice.

\section{Copeptin}

Copeptin was detected in 1972 in the posterior pituitary of pigs $(27,28)$. It derives from the precursor protein prepro-vasopressin together with AVP and neurophysin II and is a 39 amino acid long glycosylated peptide with a leucine-rich core region $(28,29)$. Its molecular mass is around $5 \mathrm{kDa}$ (30) (Fig. 1).

AVP has been characterized as the main hormone for the regulation of body fluid homeostasis and vascular tonus as well as an endocrine stress hormone $(31,32)$. In contrast, the physiological function of copeptin is largely unknown. It has been proposed to have a role as prolactin-releasing factor, but this could not be confirmed $(33,34)$. Another function could be the involvement of copeptin in the folding of the AVP precursor, as it seems to interact with the calnexin-calreticulin system in the endoplasmic reticulum $(35,36)$. Accordingly, a possible relationship between certain forms of familial DI and the inefficient folding of the AVP precursor in the absence of copeptin was proposed (8); however, further examinations are needed. Today, the main use of copeptin is its role as a stable surrogate marker for AVP concentrations in humans (30).

A strong correlation between plasma AVP (when measured with a well-established radioimmunoassay) and copeptin levels has been demonstrated in healthy volunteers with a correlation index of $r=0.8$ (37). Notably, the correlation with plasma osmolality was even stronger for copeptin than for AVP (Fig. 2A and B).

The main stimuli for copeptin are similar to AVP, that is an increase in osmolality and a decrease in arterial blood volume and pressure $(37,38)$. The osmotic

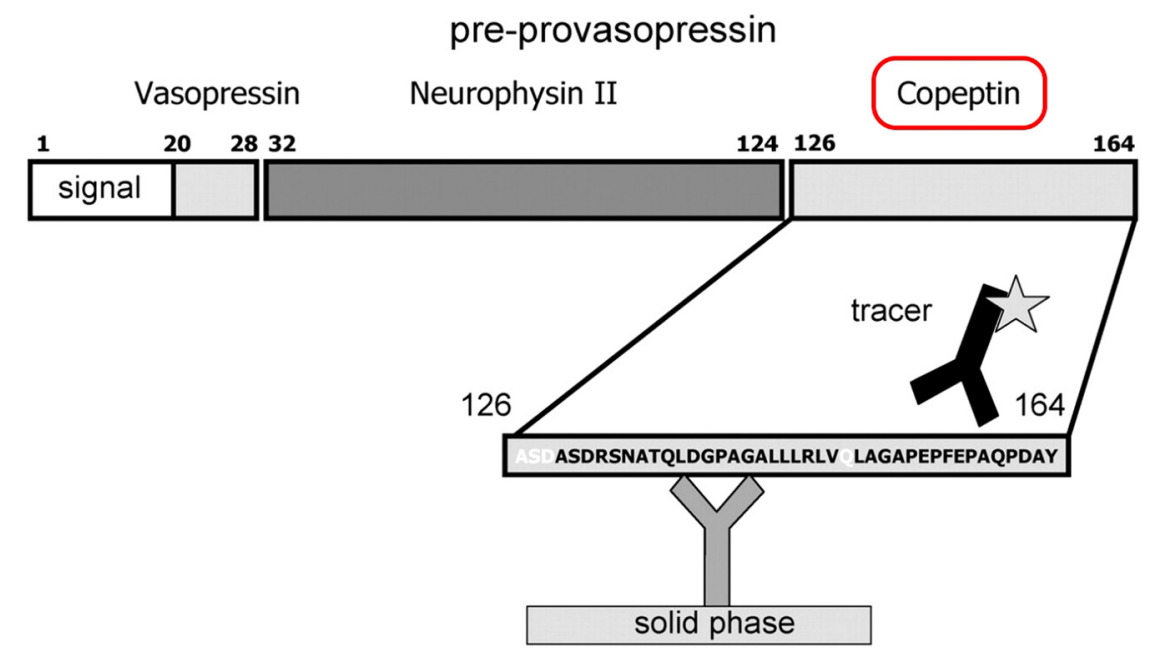

\section{Figure 1}

Structure of pre-provasopressin. The prohormone is packaged into neurosecretory granules of magnocellular neurons. During axonal transport of the granules from the hypothalamus to the posterior pituitary, enzymatic cleavage of the prohormone generates the final products: AVP, neurophysin and the $\mathrm{COOH}$-terminal glycoprotein copeptin. Modified from (30) with permission. 

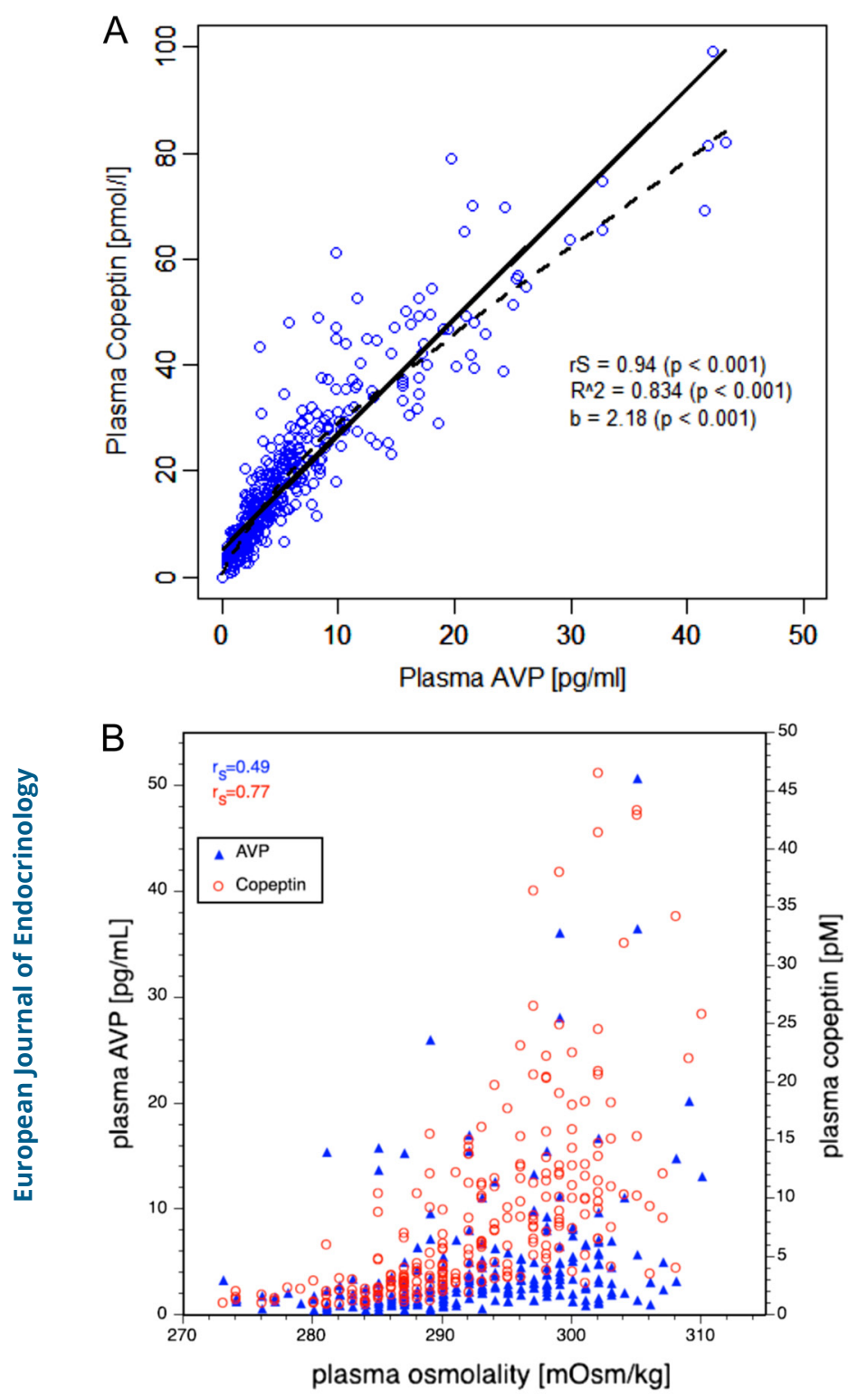

\section{Figure 2}

Correlation of arginine vasopressin (AVP) and copeptin (A) and correlation of AVP and copeptin with plasma osmolality (B). Plasma AVP and copeptin concentrations measured during water load and hypertonic saline tests are shown as scatter plot. rS denotes Spearman's rank correlation coefficients. Modified from $(37,39)$ with permission.

trigger of copeptin secretion was first shown in a study with 24 healthy adults, were fluid deprivation as well as hypertonic saline infusion lead to a significant increase in plasma copeptin levels (38). Importantly, we recently showed that copeptin is released in equimolar amounts to AVP in response to osmotic stimulation (with $3 \%$ saline infusion), again confirming its high potential as an AVP surrogate for differentiation of osmotic disorders (39).

Conversely, hypotonic saline infusion lead to a prompt suppression of plasma copeptin levels in healthy volunteers (38), similar to an oral water load (37). The prompt response of copeptin secretion upon volume depletion was shown in a baboon model of experimental hemorrhagic shock (40), where plasma copeptin concentration rapidly increased from median levels of $7.5-269 \mathrm{pmol} / \mathrm{L}$, with a subsequent decline to $27 \mathrm{pmol} / \mathrm{L}$ after reperfusion.

In addition to osmotic stimulation and arterial pressure, somatic stress as seen in all states of serious illness is also a determinant of copeptin regulation. Several observational studies confirmed the predictive character of plasma copeptin as an unspecific stress marker in various states of acute diseases, including ischemic stroke, myocardial infarction and lower respiratory tract infections $(41,42,43)$. We showed that copeptin even more subtly reflects individual stress level than plasma cortisol in patients with increasing disease-related stress (44). Compared to somatic stress, the influence of psychological stress on copeptin release seems to be rather limited, though existent, as shown by recent studies in medical students tested before and after the written exam and upon a psychological stress test $(45,46)$. Increased levels of plasma copeptin were also reported in response to physical exercise, but levels did not exceed the 99th percentile of the normal range $(47,48)$.

The half-life of AVP is between 10 and $44 \mathrm{~min}$, depending on the state of hydration, the chosen test method, species and the specificity of immunoassays. We recently showed that copeptin has a two-times-longer half-life in relation to AVP (39). The different half-lives of copeptin and AVP most likely reflect the metabolic clearance rates of these peptides. Other than AVP, which is inactivated by plasma and tissue endopeptidases in the kidney and particularly in the liver (49), the catabolism of copeptin has never been evaluated. The fact that copeptin does not accumulate as a junk protein in the circulation, and that its elimination stops once removed from the circulation, argues against the role of circulating proteases. Theoretically, because of its small size, it could be cleared by the kidneys. In fact, recent data show that copeptin is at least partly eliminated by the kidneys (50) and that in patients with chronic kidney disease, plasma copeptin levels inversely correlate with decreasing glomerular filtration rate suggesting a renal clearance of copeptin (51). 
The normal range of plasma copeptin levels has been established in two large clinical trials evaluating healthy volunteers under normo-osmotic conditions. In the first study including 359 subjects, plasma copeptin levels ranged from 1.0 to $13.8 \mathrm{pmol} / \mathrm{L}$ with a median concentration of $4.2 \mathrm{pmol} / \mathrm{L}$ (30). The second evaluation with over 700 randomly selected volunteers reported comparable results with plasma copeptin levels ranging from 1.0 to $13.0 \mathrm{pmol} / \mathrm{L}$ (52). Both studies reported higher median plasma copeptin levels in men than in women; however, no correlation with age was shown $(30,52)$. Interestingly, the difference between men and women is not present in the hyperosmolar range (39).

While copeptin levels show no significant variation in response to circadian rhythm $(53,54)$, menstrual cycle (55) or digestion, levels significantly decreased from 4.9 to $3.2 \mathrm{pmol} / \mathrm{L}$ even to small amounts of oral fluid intake (200-300 mL) (56), which has to be considered for interpretation of values in clinical practice.

In contrast to AVP, copeptin can be measured in clinical routine with commercially available assays with high-standard technical performance. Two assay are available, on one side the original manual sandwich immunoluminometric assay (LIA) (30) and on the other hand the automated immunofluorescent successor (on the KRYPTOR platform). Advantages of copeptin measurement as opposed to AVP are that it requires only a small sample volume $(50 \mu \mathrm{L}$ of serum or plasma), no extraction step or other preanalytical procedures is needed and that results are usually available in $0.5-2.5 \mathrm{~h}$. Copeptin is much more stable in plasma or serum ex vivo with less than $20 \%$ loss of recovery for at least 7 days at room temperature and at 14 days at $4^{\circ} \mathrm{C}$ making the handling of patient blood samples less complicated.

\section{Copeptin in the differential diagnosis of polyuria polydipsia syndrome}

With the development of the copeptin assay, an easy to measure, fast and reliable AVP surrogate with high ex vivo stability $(30,37,57)$, the focus returned once more to the direct test method.

In a first study, Fenske et al. aimed to increase the diagnostic accuracy of the water deprivation test by combining it with copeptin measurement (16). In their cohort of 50 patients with polyuria polydipsia syndrome, baseline plasma copeptin levels $>20 \mathrm{pmol} / \mathrm{L}$ diagnosed patients with nephrogenic DI, while levels $<2.6 \mathrm{pmol} / \mathrm{L}$ after an overnight water deprivation test indicated central
DI. A ratio of the $\Delta$ plasma copeptin levels (before and after the water deprivation phase) to the plasma sodium level at the end of the test showed a high diagnostic accuracy of $94 \%$ in differentiating patients with central DI from patients with primary polydipsia (16).

In an evaluation of 55 patients with nephrogenic or central DI or primary polydipsia, we described copeptin further as a promising new tool for the diagnosis of polyuria polydipsia syndrome (58). This study confirmed in a larger patient number that patients with nephrogenic DI can be easily diagnosed by using a single baseline copeptin level of $>21.4 \mathrm{pmol} / \mathrm{L}$ without prior thirsting. Baseline copeptin values in the other entities (i.e. central DI and primary polydipsia) however largely overlapped. Here, we showed that osmotically stimulated copeptin levels of $>4.9 \mathrm{pmol} / \mathrm{l}$ differentiated patients with central DI from patients with primary polydipsia with a high diagnostic accuracy of 96\%. Osmotic stimulation was performed using a standardized combined water deprivation followed by $3 \%$ saline infusion test aiming at an increase of plasma sodium levels above $147 \mathrm{mmol} / \mathrm{L}$. The simultaneous evaluation of AVP measurement showed a lower diagnostic differentiation with a diagnostic accuracy of only $80 \%$ accuracy, which was especially low for differentiation between partial central DI and primary polydipsia (44\%).

We recently validated the copeptin cut-off generated in this study in an international multicenter trial including 156 patients with DI or primary polydipsia (11). In contrast to the studies described above, the test protocol was further simplified in using only the 3\% saline infusion without prior thirsting, aiming at a plasma sodium level of at least $150 \mathrm{mmol} / \mathrm{L}$.

Specifically, hypertonic saline was initially given as a bolus dose of $250 \mathrm{~mL}$ over $10-15 \mathrm{~min}$, followed by a slower infusion rate of $0.15 \mathrm{~mL} / \mathrm{kg} / \mathrm{min}$. Serum sodium and osmolality were measured every $30 \mathrm{~min}$ and the infusion was terminated once the serum sodium was $>150 \mathrm{mmol} / \mathrm{L}$. At this point, copeptin was measured and the patient was asked to drink water at $30 \mathrm{~mL} / \mathrm{kg}$ within $30 \mathrm{~min}$ followed by an intravenous infusion of $5 \%$ glucose at $500 \mathrm{~mL} / \mathrm{h}$ for $1 \mathrm{~h}$. Serum sodium was once more measured after completing the $5 \%$ glucose infusion to ensure its return to normal values (11).

Under this osmotic stimulation, $97 \%$ of the patients were correctly diagnosed using the copeptin cut-off level of $>4.9 \mathrm{pmol} / \mathrm{L}$ (Fig. 3). The diagnostic accuracy was similarly accurate in distinguishing patients with partial DI from patients with primary polydipsia with a correct diagnosis in 95\%. Again, copeptin levels 


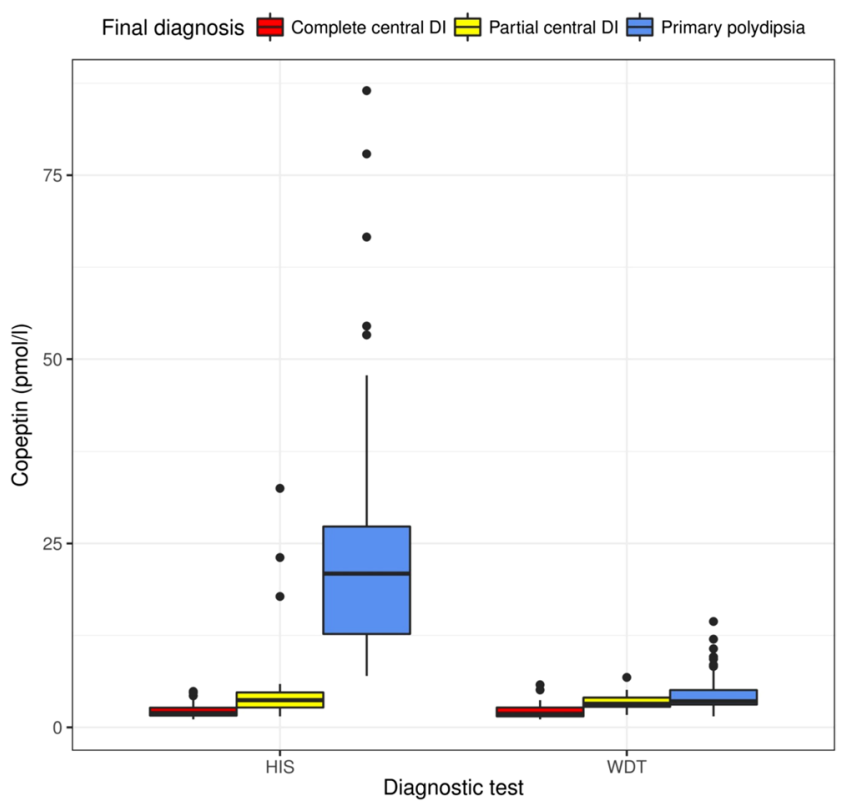

\section{Figure 3}

Stimulated copeptin levels in response to the hypertonic saline infusion and water deprivation test in patients with polyuria polydipsia syndrome. Shown are stimulated copeptin levels in response to the hypertonic saline infusion test (HIS) and water deprivation test (WDT) in patients with polyuria polydipsia syndrome that was caused by complete central diabetes insipidus (DI) or partial central diabetes insipidus as compared with primary polydipsia. The horizontal line in each box represents the median, the lower and upper boundaries of the boxes the interquartile range, the ends of the whisker lines the minimum and maximum values within 1.5 times the interquartile range and the dots outliers. Modified from (11) with permission.

of all three included patients with nephrogenic DI exceeded the cut-off level of $21.4 \mathrm{pmol} / \mathrm{L}$. Contrary to the study of Fenske described earlier, the proposed copeptin-sodium ratio did not improve the diagnostic accuracy of the water deprivation test (16), resulting in a diagnostic accuracy of only $44 \%$ (11). The proposed copeptin cut-off level of $<2.6 \mathrm{pmol} / \mathrm{L}$ after an overnight water deprivation test to diagnose complete central DI had a diagnostic accuracy of $78 \%$. The fact that the determination of copeptin after water deprivation alone does not lead to an improved diagnostic accuracy is most likely due to the inadequate osmotic stimulation. This observation is confirmed by the fact that most patients in the study did not reach hyperosmotic plasma sodium levels during the classical water deprivation test.
Accordingly, osmotic stimulation by hypertonic saline solution is needed to obtain reliable copeptin measurements. It is however important to note that hypertonic saline infusion requires close monitoring of sodium levels to ensure increase of plasma sodium levels into the hyperosmotic range $(3,59)$ while preventing osmotic overstimulation (11). In settings where regular and rapid sodium monitoring is not possible, the hypertonic saline test should not be performed. Also, it might be prudent for clinical practice to aim at a plasma sodium level $>147 \mathrm{mmol} / \mathrm{L}$ instead of $150 \mathrm{mmol} / \mathrm{L}$. Rapid normalization of sodium levels after the osmotic stimulation is also crucial to guarantee the safety of the test (11). Based on these results, it was concluded that the hypertonic saline test plus copeptin measurement might replace the classical water deprivation test in the future differential diagnosis of hypotonic polyuria (60). The recommended new algorithm for the differential diagnosis of polyuria polydipsia syndrome is displayed in Fig. 4.

Importantly, the majority of patients preferred the hypertonic saline stimulation with copeptin measurement over the classical water deprivation test, although side effects were slightly more common in the hypertonic saline test phase. Most probably, the reason was the much shorter test duration (approximately $2 \mathrm{~h}$ for the hypertonic saline test vs $17 \mathrm{~h}$ for the water deprivation test) (11).

In conclusion, copeptin is a valuable and reliable diagnostic marker in the differential diagnosis of polyuria polydipsia syndrome. In a patient with unclear hypotonic polyuria and polydipsia, determination of basal copeptin levels is recommended to exclude nephrogenic DI. In patients with high suspicion of complete central DI, an

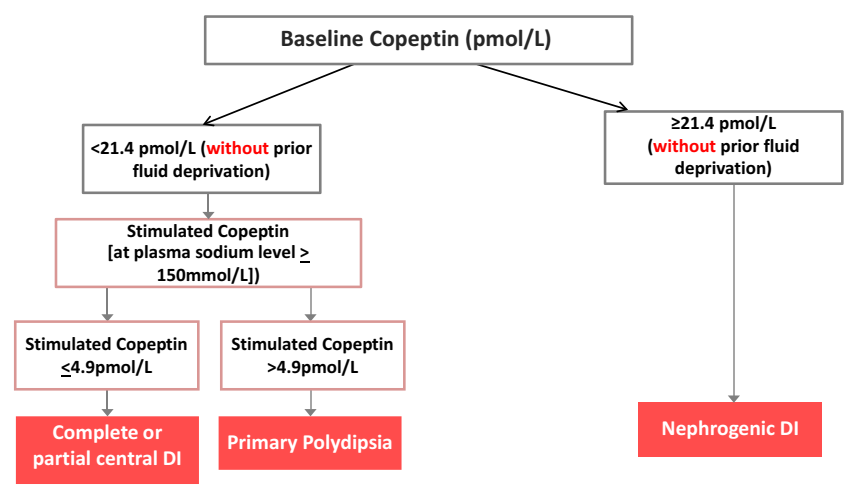

Figure 4

New algorithm for the differential diagnosis of polyuria polydipsia syndrome. Modified from (2). 
overnight water deprivation test might confirm diagnosis provided urine osmolality remains below $300 \mathrm{mosm} / \mathrm{kg}$ and plasma sodium levels increase above $147 \mathrm{mmol} / \mathrm{L}$. In all other patients, copeptin measurement after osmotic stimulation with $3 \%$ saline solution aiming at a plasma sodium level above $147 \mathrm{mmol} / \mathrm{L}$ is recommended.

Importantly, close monitoring of plasma sodium levels is needed to ascertain a diagnostically meaningful increase in plasma sodium within the hyperosmotic range while preventing a marked increase, to which females appear to be more vulnerable than males (11).

\section{Copeptin in the diagnosis of postsurgical DI}

An additional characteristic of copeptin is its use as a predictive marker for the development of postoperative DI after pituitary surgery. In a first proof-of-concept study in 2007, we used the insulin tolerance test and showed that copeptin measured during insulin-induced hypoglycemia remains low in patients with DI while increasing in patients with intact posterior pituitary function. Specifically, a copeptin level $<4.75 \mathrm{pmol} / \mathrm{L}$ identified patients with complete central DI at 3 months after transsphenoidal pituitary surgery with a high accuracy (61).

However, hypoglycemic stimulated copeptin is not feasible as a routine postoperative test for DI as it may be associated with severe hypoglycemia which is contraindicated in patients with cardiovascular disease or seizure history as well as during immediate postoperative recovery. In fact, surgery itself is a stressful event known to stimulate hypothalamic stress hormone release including AVP (62). We therefore hypothesized that pituitary surgery itself can be used as a 'stress test' to assess the functionality of AVP and copeptin secretion. We performed a prospective multicenter trial including 205 patients undergoing pituitary surgery. The $24 \%$ who developed central DI had significantly lower copeptin levels on the first postoperative day compared to patients with an uneventful course. The post hoc derived copeptin cut-off level of $<2.5 \mathrm{pmol} / \mathrm{L}$ had a positive predictive value for development of postoperative DI of $81 \%$ and a specificity of $97 \%$, while a level $>30 \mathrm{pmol} / \mathrm{L}$ excluded it with a negative predictive value of $95 \%$ and a sensitivity of $94 \%$ (Fig. 5). Accordingly, copeptin measurement after pituitary surgery is helpful to predict the onset of central DI and may therefore be a novel marker for early goal-directed management of postoperative DI.

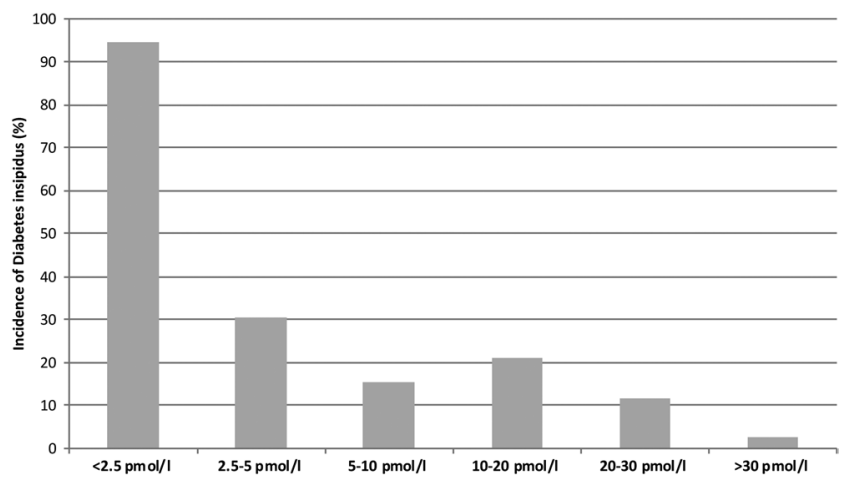

Figure 5

Copeptin levels upon pituitary surgery. A copeptin cut-off level of $<2.5 \mathrm{pmol} / \mathrm{L}$, measured within the first $12 \mathrm{~h}$ after surgery, had a positive predictive value for development of postoperative diabetes insipidus of $81 \%$ and a specificity of 97\%; while a level $>30 \mathrm{pmol} / \mathrm{L}$ excluded it with a negative predictive value of $95 \%$ and a sensitivity of $94 \%$. Modified from (69) with permission.

\section{Conclusions and future prospects}

In conclusion, the availability of copeptin has led to a 'revival' of the direct test in the differential diagnosis of the polyuria polydipsia syndrome. Copeptin is a stable surrogate marker of AVP able to identify patients with nephrogenic DI with a baseline measurement without prior thirsting. For the differentiation of central DI and primary polydipsia, osmotic stimulation with hypertonic saline is needed, with a copeptin cut-off of $4.9 \mathrm{pmol} / \mathrm{L}$ differentiating these two entities with a high diagnostic accuracy.

To further simplify the algorithm, an alternative stimulation of the neurohypophysis without the necessity of constant monitoring of plasma sodium levels would be preferable. Arginine infusion is known to stimulate various hormones secreted by the anterior pituitary gland such as growth hormone and prolactin $(63,64)$. It is therefore used as a standard test in the evaluation of suspected growth hormone deficiency in children and adult patients $(65,66,67)$. We therefore hypothesized that arginine would also be a stimulus for copeptin secretion and could differentiate between central DI and primary polydipsia. Indeed, our recent data in patients with central DI or primary polydipsia (68) showed that arginine is a potent stimulator of the neurohypophysis with consecutive copeptin secretion. Measurement of plasma copeptin levels after arginine infusion was able to differentiate patients with primary polydipsia from patients with central DI with a high diagnostic accuracy. 
These findings are particularly notable with regard to the generally good tolerability of the arginine infusion and short test duration of $2 \mathrm{~h}$. Therefore, in the future, arginine stimulated copeptin measurement could further simplify the differential diagnosis of polyuria polydipsia syndrome.

\section{Declaration of interest}

M C C received speaker honoraria from Thermofisher AG, the manufacturer of the Copeptin assay.

\section{Funding}

M Christ-Crain was supported by a grant from the Swiss National Science Foundation (SNF-162608) and the University Hospital Basel, Switzerland.

\section{References}

1 Robertson GL. Diabetes insipidus. Endocrinology and Metabolism Clinics of North America 199524 549-572. (https://doi.org/10.1016/ S0889-8529(18)30031-8)

2 Christ-Crain M \& Fenske W. Copeptin in the diagnosis of vasopressin-dependent disorders of fluid homeostasis. Nature Reviews: Endocrinology 201612 168-176. (https://doi.org/10.1038/ nrendo.2015.224)

3 Robertson GL. The regulation of vasopressin function in health and disease. Recent Progress in Hormone Research 197633 333-385.

4 Miller M, Dalakos T, Moses AM, Fellerman H \& Streeten DH. Recognition of partial defects in antidiuretic hormone secretion. Annals of Internal Medicine 197073 721-729. (https://doi. org/10.7326/0003-4819-73-5-721)

5 Bockenhauer D \& Bichet DG. Pathophysiology, diagnosis and management of nephrogenic diabetes insipidus. Nature Reviews: Nephrology 201511 576-588. (https://doi.org/10.1038/nrneph.2015.89)

6 Nemergut EC, Zuo Z, Jane JA Jr \& Laws ER Jr. Predictors of diabetes insipidus after transsphenoidal surgery: a review of 881 patients. Journal of Neurosurgery 2005103 448-454. (https://doi.org/10.3171/ jns.2005.103.3.0448)

7 Babey M, Kopp P \& Robertson GL. Familial forms of diabetes insipidus: clinical and molecular characteristics. Nature Reviews: Endocrinology 20117 701-714. (https://doi.org/10.1038/ nrendo.2011.100)

8 Birk J, Friberg MA, Prescianotto-Baschong C, Spiess M \& Rutishauser J. Dominant pro-vasopressin mutants that cause diabetes insipidus form disulfide-linked fibrillar aggregates in the endoplasmic reticulum. Journal of Cell Science 2009122 3994-4002. (https://doi. org/10.1242/jcs.051136)

9 Thompson CJ \& Baylis PH. Thirst in diabetes insipidus: clinical relevance of quantitative assessment. Quarterly Journal of Medicine 198765 853-862.

10 Sailer CO, Winzeler B, Nigro N, Suter-Widmer I, Arici B, Bally M, Schuetz P, Mueller B \& Christ-Crain M. Characteristics and outcomes of patients with profound hyponatraemia due to primary polydipsia. Clinical Endocrinology 201787 492-499. (https://doi.org/10.1111/ cen.13384)

11 Fenske W, Refardt J, Chifu I, Schnyder I, Winzeler B, Drummond J, Ribeiro-Oliveira A Jr, Drescher T, Bilz S, Vogt DR et al. A copeptinbased approach in the diagnosis of diabetes insipidus. New England Journal of Medicine 2018379 428-439. (https://doi.org/10.1056/ NEJMoa1803760)
12 Epstein FH, Kleeman CR \& Hendrikx A. The influence of bodily hydration on the renal concentrating process. Journal of Clinical Investigation 195736 629-634. (https://doi.org/10.1172/JCI103462)

13 Fenske W \& Allolio B. Clinical review: current state and future perspectives in the diagnosis of diabetes insipidus: a clinical review. Journal of Clinical Endocrinology and Metabolism 201297 3426-3437. (https://doi.org/10.1210/jc.2012-1981)

14 Carter AC \& Robbins J. The use of hypertonic saline infusions in the differential diagnosis of diabetes insipidus and psychogenic polydipsia. Journal of Clinical Endocrinology and Metabolism $1947 \mathbf{7}$ 753-766. (https://doi.org/10.1210/jcem-7-11-753)

15 Barlow ED \& De Wardener HE. Compulsive water drinking. Quarterly Journal of Medicine 195928 235-258.

16 Fenske W, Quinkler M, Lorenz D, Zopf K, Haagen U, Papassotiriou J, Pfeiffer AF, Fassnacht M, Stork S \& Allolio B. Copeptin in the differential diagnosis of the polydipsia-polyuria syndrome revisiting the direct and indirect water deprivation tests. Journal of Clinical Endocrinology and Metabolism 201196 1506-1515. (https:// doi.org/10.1210/jc.2010-2345)

17 Palevsky PM, Bhagrath R \& Greenberg A. Hypernatremia in hospitalized patients. Annals of Internal Medicine 1996124 197-203. (https://doi.org/10.7326/0003-4819-124-2-199601150-00002)

18 Fujisawa I, Nishimura K, Asato R, Togashi K, Itoh K, Noma S, Kawamura Y, Sago T, Minami S \& Nakano Y. Posterior lobe of the pituitary in diabetes insipidus: MR findings. Journal of Computer Assisted Tomography 198711 221-225.

19 Arslan A, Karaarslan E \& Dincer A. High intensity signal of the posterior pituitary. A study with horizontal direction of frequencyencoding and fat suppression MR techniques. Acta Radiologica 1999 40 142-145. (https://doi.org/10.3109/02841859909177729)

20 Moses AM, Clayton B \& Hochhauser L. Use of T1-weighted MR imaging to differentiate between primary polydipsia and central diabetes insipidus. American Journal of Neuroradiology 199213 1273-1277.

21 Cote M, Salzman KL, Sorour M \& Couldwell WT. Normal dimensions of the posterior pituitary bright spot on magnetic resonance imaging. Journal of Neurosurgery 2014120 357-362. (https://doi. org/10.3171/2013.11.JNS131320)

22 Ranadive SA, Ersoy B, Favre H, Cheung CC, Rosenthal SM, Miller WL $\&$ Vaisse C. Identification, characterization and rescue of a novel vasopressin-2 receptor mutation causing nephrogenic diabetes insipidus. Clinical Endocrinology 200971 388-393. (https://doi. org/10.1111/j.1365-2265.2008.03513.x)

23 Hannon MJ, Orr C, Moran C, Behan LA, Agha A, Ball SG \& Thompson CJ. Anterior hypopituitarism is rare and autoimmune disease is common in adults with idiopathic central diabetes insipidus. Clinical Endocrinology 201276 725-728. (https://doi. org/10.1111/j.1365-2265.2011.04270.x)

24 Zerbe RL \& Robertson GL. A comparison of plasma vasopressin measurements with a standard indirect test in the differential diagnosis of polyuria. New England Journal of Medicine 1981305 1539-1546. (https://doi.org/10.1056/NEJM198112243052601)

25 Baylis PH, Gaskill MB \& Robertson GL. Vasopressin secretion in primary polydipsia and cranial diabetes insipidus. Quarterly Journal of Medicine 198150 345-358.

26 Milles JJ, Spruce B \& Baylis PH. A comparison of diagnostic methods to differentiate diabetes insipidus from primary polyuria: a review of 21 patients. Acta Endocrinologica 1983 104 410-416. (https://doi. org/10.1530/acta.0.1040410)

27 Holwerda DA. A glycopeptide from the posterior lobe of pig pituitaries. I. Isolation and characterization. European Journal of Biochemistry/FEBS 197228 334-339.

28 Levy B, Chauvet MT, Chauvet J \& Acher R. Ontogeny of bovine neurohypophysial hormone precursors. II. Foetal copeptin, the third domain of the vasopressin precursor. International Journal of Peptide and Protein Research 198627 320-324. 
29 Land H, Schutz G, Schmale H \& Richter D. Nucleotide sequence of cloned cDNA encoding bovine arginine vasopressinneurophysin II precursor. Nature 1982295 299-303. (https://doi. org/10.1038/295299a0)

30 Morgenthaler NG, Struck J, Alonso C \& Bergmann A. Assay for the measurement of copeptin, a stable peptide derived from the precursor of vasopressin. Clinical Chemistry 200652 112-119. (https://doi.org/10.1373/clinchem.2005.060038)

31 Nathanson MH, Moyer MS, Burgstahler AD, O'Carroll AM, Brownstein MJ \& Lolait SJ. Mechanisms of subcellular cytosolic Ca2+ signaling evoked by stimulation of the vasopressin V1a receptor. Journal of Biological Chemistry 1992267 23282-23289.

32 Baylis PH. Osmoregulation and control of vasopressin secretion in healthy humans. American Journal of Physiology 1987253 R671-R678. (https://doi.org/10.1152/ajpregu.1987.253.5.R671)

33 Nagy G, Mulchahey JJ, Smyth DG \& Neill JD. The glycopeptide moiety of vasopressin-neurophysin precursor is neurohypophysial prolactin releasing factor. Biochemical and Biophysical Research Communications 1988151 524-529. (https://doi.org/10.1016/0006291X(88)90625-0)

34 Hyde JF, North WG \& Ben-Jonathan N. The vasopressin-associated glycopeptide is not a prolactin-releasing factor: studies with lactating Brattleboro rats. Endocrinology 1989125 35-40. (https://doi. org/10.1210/endo-125-1-35)

35 Barat C, Simpson L \& Breslow E. Properties of human vasopressin precursor constructs: inefficient monomer folding in the absence of copeptin as a potential contributor to diabetes insipidus. Biochemistry 200443 8191-8203. (https://doi.org/10.1021/bi0400094)

36 Parodi AJ. Protein glucosylation and its role in protein folding. Annual Review of Biochemistry 200069 69-93. (https://doi. org/10.1146/annurev.biochem.69.1.69)

37 Balanescu S, Kopp P, Gaskill MB, Morgenthaler NG, Schindler C $\&$ Rutishauser J. Correlation of plasma copeptin and vasopressin concentrations in hypo-, iso-, and hyperosmolar States. Journal of Clinical Endocrinology and Metabolism 201196 1046-1052. (https:// doi.org/10.1210/jc.2010-2499)

38 Szinnai G, Morgenthaler NG, Berneis K, Struck J, Muller B, Keller U \& Christ-Crain M. Changes in plasma copeptin, the C-terminal portion of arginine vasopressin during water deprivation and excess in healthy subjects. Journal of Clinical Endocrinology and Metabolism 2007 92 3973-3978. (https://doi.org/10.1210/jc.2007-0232)

39 Fenske WK, Schnyder I, Koch G, Walti C, Pfister M, Kopp P, Fassnacht M, Strauss K \& Christ-Crain M. Release and decay kinetics of copeptin vs AVP in response to osmotic alterations in healthy volunteers. Journal of Clinical Endocrinology and Metabolism 2018103 505-513. (https://doi.org/10.1210/jc.2017-01891)

40 Morgenthaler NG, Muller B, Struck J, Bergmann A, Redl H \& ChristCrain M. Copeptin, a stable peptide of the arginine vasopressin precursor, is elevated in hemorrhagic and septic shock. Shock 2007 28 219-226. (https://doi.org/10.1097/SHK.0b013e318033e5da)

41 Katan M, Fluri F, Morgenthaler NG, Schuetz P, Zweifel C, Bingisser R, Muller K, Meckel S, Gass A, Kappos L et al. Copeptin: a novel, independent prognostic marker in patients with ischemic stroke. Annals of Neurology 200966 799-808. (https://doi.org/10.1002/ ana.21783)

42 Reichlin T, Hochholzer W, Stelzig C, Laule K, Freidank H, Morgenthaler NG, Bergmann A, Potocki M, Noveanu M, Breidthardt $\mathrm{T}$ et al. Incremental value of copeptin for rapid rule out of acute myocardial infarction. Journal of the American College of Cardiology 200954 60-68. (https://doi.org/10.1016/j. jacc.2009.01.076)

43 Katan M \& Christ-Crain M. The stress hormone copeptin: a new prognostic biomarker in acute illness. Swiss Medical Weekly 2010140 w13101. (https://doi.org/10.4414/smw.2010.13101)

44 Katan M, Morgenthaler N, Widmer I, Puder JJ, Konig C, Muller B $\&$ Christ-Crain M. Copeptin, a stable peptide derived from the vasopressin precursor, correlates with the individual stress level. Neuro Endocrinology Letters 200829 341-346.

45 Siegenthaler J, Walti C, Urwyler SA, Schuetz P \& Christ-Crain M. Copeptin concentrations during psychological stress: the PsyCo study. European Journal of Endocrinology 2014171 737-742. (https:// doi.org/10.1530/EJE-14-0405)

46 Urwyler SA, Schuetz P, Sailer C \& Christ-Crain M. Copeptin as a stress marker prior and after a written examination - the CoEXAM study. Stress 201518 134-137. (https://doi.org/10.3109/10253890.2014.993 966)

47 Maeder MT, Staub D, Brutsche MH, Arenja N, Socrates T, Reiter M, Meissner J, Morgenthaler NG, Bergmann A, Struck J et al. Copeptin response to clinical maximal exercise tests. Clinical Chemistry 2010 56 674-676. (https://doi.org/10.1373/clinchem.2009.136309)

48 Hew-Butler T, Hoffman MD, Stuempfle KJ, Rogers IR, Morgenthaler NG \& Verbalis JG. Changes in copeptin and bioactive vasopressin in runners with and without hyponatremia. Clinical Journal of Sport Medicine 201121 211-217. (https://doi.org/10.1097/ JSM.0b013e31821a62c2)

49 Robertson GL. Antidiuretic hormone. Normal and disordered function. Endocrinology and Metabolism Clinics of North America 2001 30 671-694, vii.

50 Nakajima A, Lu Y, Kawano H, Horie S \& Muto S. Association of arginine vasopressin surrogate marker urinary copeptin with severity of autosomal dominant polycystic kidney disease (ADPKD). Clinical and Experimental Nephrology 201519 1199-1205. (https://doi. org/10.1007/s10157-015-1101-7)

51 Roussel R, Fezeu L, Marre M, Velho G, Fumeron F, Jungers P, Lantieri O, Balkau B, Bouby N, Bankir L et al. Comparison between copeptin and vasopressin in a population from the community and in people with chronic kidney disease. Journal of Clinical Endocrinology and Metabolism 201499 4656-4663. (https://doi. org/10.1210/jc.2014-2295)

52 Bhandari SS, Loke I, Davies JE, Squire IB, Struck J \& Ng LL. Gender and renal function influence plasma levels of copeptin in healthy individuals. Clinical Science 2009116 257-263. (https://doi. org/10.1042/CS20080140)

53 Darzy KH, Dixit KC, Shalet SM, Morgenthaler NG \& Brabant G. Circadian secretion pattern of copeptin, the C-terminal vasopressin precursor fragment. Clinical Chemistry 201056 1190-1191. (https:// doi.org/10.1373/clinchem.2009.141689)

54 Beglinger S, Drewe J \& Christ-Crain M. The circadian rhythm of copeptin, the C-terminal portion of arginin vasopressin. In Poster Presentation, SGED Congress, Nov 17-18, 2016, Bern, Switzerland, 2016.

55 Puder JJ, Blum CA, Mueller B, De Geyter Ch, Dye L \& Keller U. Menstrual cycle symptoms are associated with changes in low-grade inflammation. European Journal of Clinical Investigation 200636 58-64. (https://doi.org/10.1111/j.1365-2362.2006.01591.x)

56 Walti C, Siegenthaler J \& Christ-Crain M. Copeptin levels are independent of ingested nutrient type after standardised meal administration - the CoMEAL study. Biomarkers 201419 557-562. (https://doi.org/10.3109/1354750X.2014.940504)

57 Fenske WK, Schnyder I, Koch G, Walti C, Pfister M, Kopp P, Fassnacht M, Strauss K \& Christ-Crain M. Release and decay kinetics of copeptin versus AVP in response to osmotic alterations in healthy volunteers. Journal of Clinical Endocrinology and Metabolism $2017 \mathbf{1 0 3}$ 505-513. (https://doi.org/10.1210/jc.2017-01891)

58 Timper K, Fenske W, Kuhn F, Frech N, Arici B, Rutishauser J, Kopp P, Allolio B, Stettler C, Muller B et al. Diagnostic accuracy of copeptin in the differential diagnosis of the polyuria-polydipsia syndrome: a prospective multicenter study. Journal of Clinical Endocrinology and Metabolism 2015100 2268-2274. (https://doi.org/10.1210/jc.20144507)

59 Robertson GL, Shelton RL \& Athar S. The osmoregulation of vasopressin. Kidney International 197610 25-37. (https://doi. org/10.1038/ki.1976.76) 
60 Rosen CJ \& Ingelfinger JR. A reliable diagnostic test for hypotonic polyuria. New England Journal of Medicine 2018379 483-484. (https:// doi.org/10.1056/NEJMe1808195)

61 Katan M, Morgenthaler NG, Dixit KC, Rutishauser J, Brabant GE, Muller B \& Christ-Crain M. Anterior and posterior pituitary function testing with simultaneous insulin tolerance test and a novel copeptin assay. Journal of Clinical Endocrinology and Metabolism 2007 92 2640-2643. (https://doi.org/10.1210/jc.2006-2046)

62 Widmer IE, Puder JJ, Konig C, Pargger H, Zerkowski HR, Girard J $\&$ Muller B. Cortisol response in relation to the severity of stress and illness. Journal of Clinical Endocrinology and Metabolism 200590 4579-4586. (https://doi.org/10.1210/jc.2005-0354)

63 Merimee TJ, Rabinowtitz D \& Fineberg SE. Arginine-initiated release of human growth hormone. Factors modifying the response in normal man. New England Journal of Medicine 1969280 1434-1438. (https://doi.org/10.1056/NEJM196906262802603)

64 Nair NP, Lal S, Thavundayil JX, Isaac I, Eugenio H, Achim A, Schwartz G \& Guyda H. Effect of normal aging on the prolactin response to graded doses of sulpiride and to arginine. Progress in Neuro-Psychopharmacology and Biological Psychiatry 19859 633-637. (https://doi.org/10.1016/0278-5846(85)90031-4)

65 Alba-Roth J, Muller OA, Schopohl J \& von Werder K. Arginine stimulates growth hormone secretion by suppressing endogenous somatostatin secretion. Journal of Clinical Endocrinology and Metabolism 198867 1186-1189. (https://doi.org/10.1210/jcem-67-61186)

66 Ghigo E, Bellone J, Aimaretti G, Bellone S, Loche S, Cappa M, Bartolotta E, Dammacco F \& Camanni F. Reliability of provocative tests to assess growth hormone secretory status. Study in 472 normally growing children. Journal of Clinical Endocrinology and Metabolism 199681 3323-3327. (https://doi.org/10.1210/ jcem.81.9.8784091)

67 Maghnie M, Cavigioli F, Tinelli C, Autelli M, Arico M, Aimaretti G \& Ghigo E. GHRH plus arginine in the diagnosis of acquired GH deficiency of childhood-onset. Journal of Clinical Endocrinology and Metabolism 200287 2740-2744. (https://doi.org/10.1210/ jcem.87.6.8546)

68 Winzeler B, Nigro N, Refardt J, Vogt DR, Szinnai G \& Christ-Crain M. Copeptin values after arginine infusion - a new diagnostic test for diabetes insipidus. In Oral Presentation, Endo 2018, Chicago, June 17th-20th, 2018, 2018.

69 Winzeler B, Zweifel C, Nigro N, Arici B, Bally M, Schuetz P, Blum CA, Kelly C, Berkmann S, Huber A et al. Postoperative copeptin concentration predicts diabetes insipidus after pituitary surgery. Journal of Clinical Endocrinology and Metabolism 2015100 2275-2282. (https://doi.org/10.1210/jc.2014-4527)

Received 5 March 2019

Revised version received 17 April 2019

Accepted 8 May 2019 